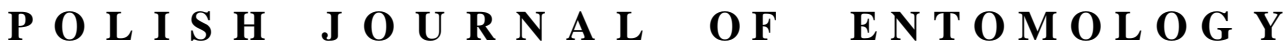

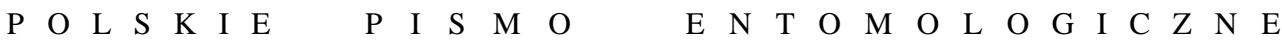

VOL. 85: 399-407

Lublin

31 December 2016

DOI: $10.1515 /$ pjen-2016-0024

\section{Biomass estimation using a length-weight relationship in beetle larvae (Coleoptera: Aphodiidae, Histeridae, Hydrophilidae, Staphylinidae) obtained from cow dung}

\author{
RADOSŁAW MROCZYŃSKI ${ }^{1 *}$, KAROL DALIGA $^{2}$ \\ ${ }^{1}$ Department of Ecology and Environmental Protection, Faculty of Biology and Biotechnology, \\ University of Warmia and Mazury, Pl. Łódzki 3, 10-727 Olsztyn, Poland \\ ${ }^{2}$ Department of Geodesy, Faculty of Civil and Environmental Engineering, Gdańsk \\ University of Technology, ul. G. Narutowicza 11/12, 80-233 Gdańsk, Poland
}

\begin{abstract}
This research enabled the relationship between length and dry body mass to be determined for 158 beetle larvae taken from cow dung in north-eastern Poland. The larvae were divided into three morphological types, for which the power and linear function of the body lengthweight relationship were determined. The linear regression equation characterizes the relationship between body weight and length for all morphological types of larvae very well $\left(0.8955 \leq \mathrm{R}^{2} \leq 0.9752\right)$. The power regression equation characterizes this relationship for all morphological types of larvae well $\left(0.8562 \leq R^{2} \leq 0.9742\right)$. The equations obtained can be used to compute dry mass for most beetle larvae inhabiting dung.
\end{abstract}

KEY WORDS: body length, body weight, biomass, Coleoptera, cow dung, larvae.

\section{INTRODUCTION}

Biomass is an important indicator of ecological processes and energy fluxes in insect ecology (SCHOWALTER 2011). Its advantage over abundance is that it better represents the energy role of species in ecosystems. The biomass of a given species is closely related to its metabolism (SAINT-GERMAIN et al. 2007). Studies on the relationship between body weight and organism size have been carried out for almost 100 years (THOMPSON 1917). An

\footnotetext{
* Corresponding author: radzio.fm@gmail.com
} 
extremely species-rich order, beetles can form assemblages frequently including thousands of individuals. Measuring the dry body mass of every individual beetle is a very laborious process, so researchers usually avail themselves of ready-made regression equations. Regression curves are plotted for species groups characterized by much the same morphology but different body lengths (ROGERS et al. 1976, ROGERS et al. 1977, MARCUZZI 1987, JAROŠIK 1989, LOBO 1993). A power equation in the following form constitutes the basis for computing the dry body mass of insects:

$$
Y=a * X^{b}
$$

where $\mathrm{Y}$ is the dry mass (mg), $\mathrm{X}$ is the length (mm), $a$ and $b$ are parameters describing the allometric relationship between these variables. This equation can also be written in the logarithmic form $\ln (Y)=b * \ln (X)-\ln (a)$, from which we obtain a linear equation. The main purpose of this work was to find regression equations for the larval stages of beetles taken from cow dung in north-eastern Poland. These equations are intended to be a rapid way of computing the dry mass of individual morphological types of larvae.

\section{MATERIALS AND METHODS}

All the beetles from the families Staphylinidae (number of individuals $n=46$ ), Aphodiidae $(n=61)$, Histeridae $(n=6)$ and Hydrophilidae $(n=45)$ were collected from cow dung in a pasture in the village of Dziarny, situated approximately $4 \mathrm{~km}$ from the town of Iława (north-east Poland, $53^{\circ} 34^{\prime} \mathrm{E}, 19^{\circ} 37^{\prime} \mathrm{N}$ ). The larvae were collected from dung of different age in June, July and August 2014, killed with ethyl acetate, cleaned, and immersed in $70 \%$ alcohol. Identification was to subfamily level. Body length was measured to an accuracy of $0.5 \mathrm{~mm}$. After desiccation at a temperature of $105^{\circ} \mathrm{C}$, the larvae were weighed to an accuracy of $0.1 \mathrm{mg}$. In the case of very small larvae, a group of individuals (2-10) with the same length and morphological structure were weighed together, after which the value obtained was divided by their number.

We distinguished three morphological types of larvae from the dung of large herbivores: (I) C-shaped larvae from Aphodiidae; (II) cylindrical or slightly flattened larvae, among which terrestrial representatives from Hydrophilidae and Histeridae can be placed; (III) distinctly oblong larvae with well-developed legs (Staphylinidae). The body lengths of the C-shaped larvae were measured from the clypeus to the end of the body bend. The length of other larvae was measured to the end of the abdomen, but without the urogomphi (Fig. 1). Body lengths of hydrophilid larvae (type II) are extremely difficult to measure and are encumbered with a larger error than in the case of the other larvae. This is because these 
larvae can easily alter their body length. The length of the same larva may differ significantly (by up to $2 \mathrm{~mm}$ ) depending on whether the body is contracted or relaxed. When measuring the larvae from this family, we made sure that they were neither fully contracted nor fully relaxed.

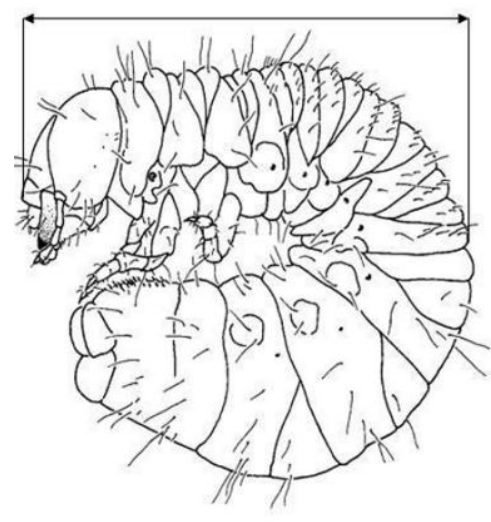

I

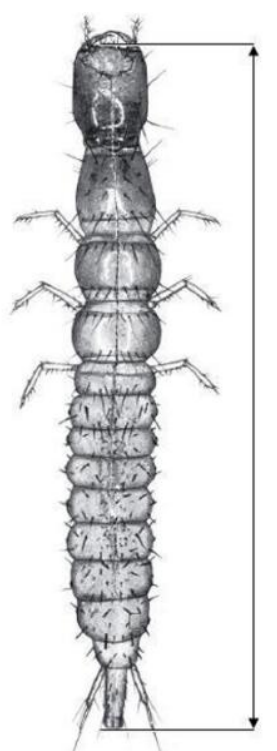

III

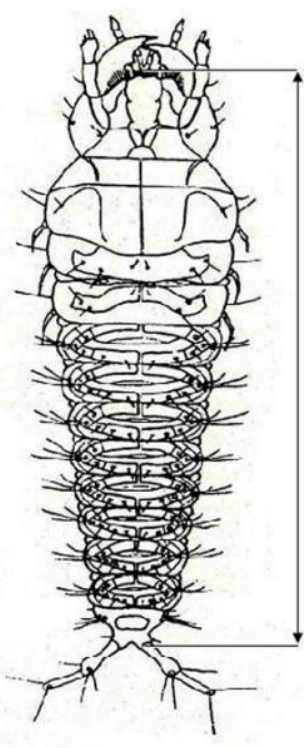

II

Fig. 1. The method used to measure the body length of three morphological types of larvae (figures taken from: I - VERDÚ \& GALANTE (1999), II - LiNDNER (1967), III - STANIEC \& PIETRYKOWSKA-TUDRUJ (2010), all modified).

The approximation with power and linear functions was carried out for each morphological larva type on the basis of length and weight measurements. Confidence curves reaching $95 \%$ were determined as well. The approximation was performed using OriginPro 9.0 software from OriginLab.

\section{RESULTS}

The equations obtained were assigned to actual morphological types of larvae found in the dung of large plant-eating animals. The parameters and regression statistics for morphological types of larvae are given in Table 1. 
Table 1. Parameters and regression statistics for three morphological types of larvae taken from cow dung $\left(S_{a}, S_{b}-\right.$ Standard error for parameters $a$ and $\left.b\right)$.

\begin{tabular}{|l|l|c|c|c|c|c|}
\hline \multicolumn{1}{|c|}{ Larvae } & $\begin{array}{c}\text { Fitting } \\
\text { function }\end{array}$ & $\boldsymbol{a}$ & $\boldsymbol{S}_{\boldsymbol{a}}$ & $\boldsymbol{b}$ & $\boldsymbol{S}_{\boldsymbol{b}}$ & $\mathbf{R}^{\mathbf{2}}$ \\
\hline \multirow{2}{*}{ Aphodiidae } & Linear & 0.02260 & 0.00340 & 3.180 & 0.075 & 0.975 \\
\cline { 2 - 7 } & Power & 0.00660 & 0.00490 & 3.720 & 0.310 & 0.907 \\
\hline \multirow{2}{*}{ Hydrophilidae and } & Linear & 0.01760 & 0.00520 & 2.580 & 0.140 & 0.896 \\
\cline { 2 - 7 } Histeridae & Power & 0.02750 & 0.01130 & 2.390 & 0.180 & 0.856 \\
\hline \multirow{2}{*}{ Staphylinidae } & Linear & 0.00160 & 0.00041 & 3.280 & 0.110 & 0.975 \\
\cline { 2 - 7 } & Power & 0.00065 & 0.00045 & 3.570 & 0.220 & 0.974 \\
\hline
\end{tabular}

The body length of the C-shaped larvae (type I, all from Aphodinae) ranged from 2.0 to $12.0 \mathrm{~mm}$, and their dry weight from 0.2 to $82.1 \mathrm{mg}$. In the case of type I larvae, the linear and power regression equation characterizes the relationship between body weight and length very well $\left(R^{2}=0.9747\right.$ and $R^{2}=0.9066$, respectively). However, the values of parameter $a$ computed for the power and linear function were significantly different ( $p$-value $=0.01, t=2.676)$. In the case of parameter $b$, we can assume that the models gave the same results $(p$-value $=0.10, t=1.702)$. The differences between the models are due primarily to the algorithms used for approximation with the assumed functions and the measured data range.

The body length of the type II larvae (Histerinae and Sphaeridinae) ranged from 5.0 to $12.0 \mathrm{~mm}$, and their dry weight from 1.0 to $10.7 \mathrm{mg}$. In the case of type II larvae, the linear and power regression equation characterizes the relationship between body weight and length well $\left(\mathrm{R}^{2}=0.8955\right.$ and $\mathrm{R}^{2}=0.8562$, respectively). The values of parameter $a$ computed for the power and linear model did not differ from each other significantly ( $p$-value $=0.43, t=0.799)$, neither are there any grounds for stating that parameter $b$ values are different $(p$-value $=0.40, t=0.853)$.

The body length of the type III larvae (Aleocharinae, Oxytelinae and Staphylininae) ranged from 4.0 to $25.0 \mathrm{~mm}$, and their dry weight from 0.1 to $69.2 \mathrm{mg}$. In the case of type III larvae, the linear and power regression equation characterizes the relationship between body weight and length very well $\left(R^{2}=0.9752\right.$ and $R^{2}=0.9742$, respectively). The values of parameter $a(p$-value $=0.13, t=1.569)$ and parameter $b(p$-value $=0.2, t=1.181)$ were not significantly different for either model.

For type I larvae, parameter $b$ reached a value of 3.18 (the value from the approximation with the linear function was chosen), whereas for type II and III larvae, parameter $b$ took values of 2.58 and 3.28, respectively (the values from the approximation with linear functions were chosen). The discrepancy between parameter $b$ values for the same larva type, but different approximating functions, is the outcome of applying various algorithms 
to linear and power function approximations (Fig. 2-4), although from the mathematical point of view, approximation with the linear and power function should yield identical results. In practice, this is only so when we have a lot of measurement data and the values are "evenly distributed". One is therefore justified in using the approximation with the linear function, which is simpler in computations.
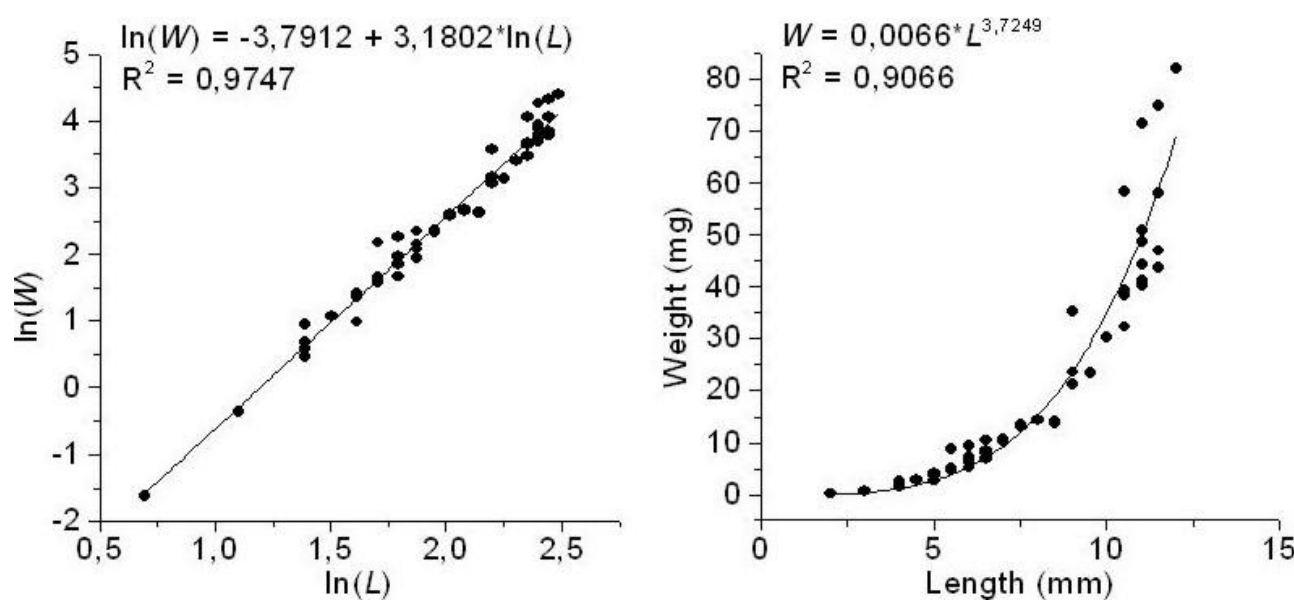

Fig. 2. Length-weight linear regression (left) and power regression (right) for type I larvae.
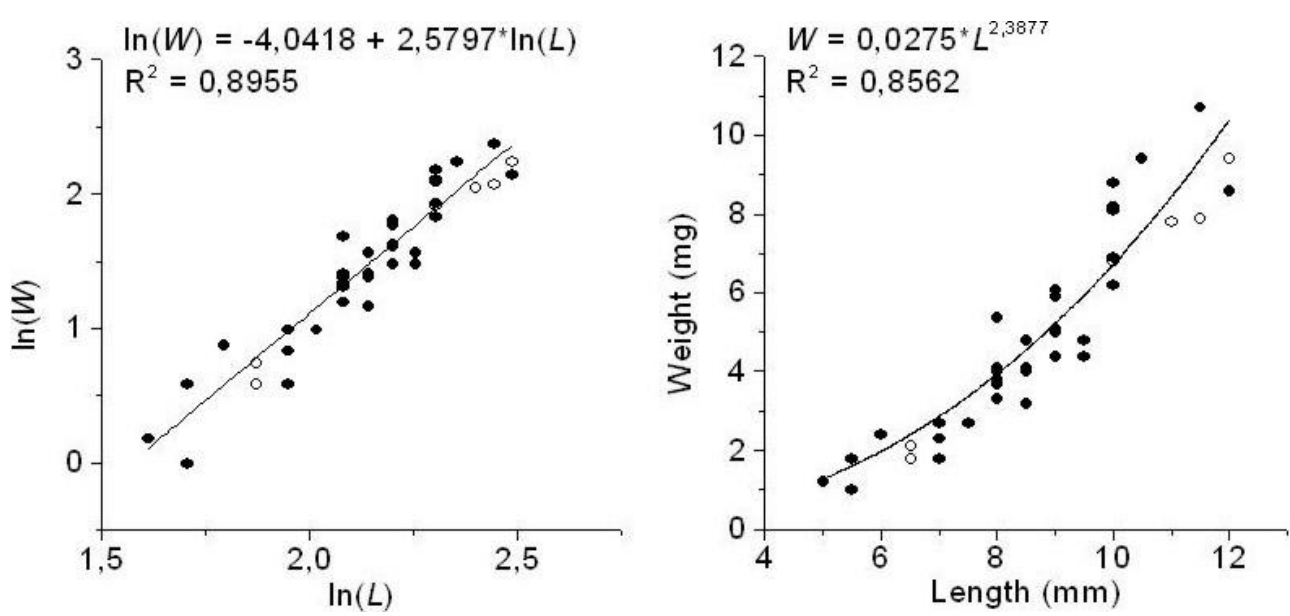

Fig. 3. Length-weight linear regression (left) and power regression (right) for type II larvae. Solid circle: Hydrophilidae, open circle: Histeridae. 

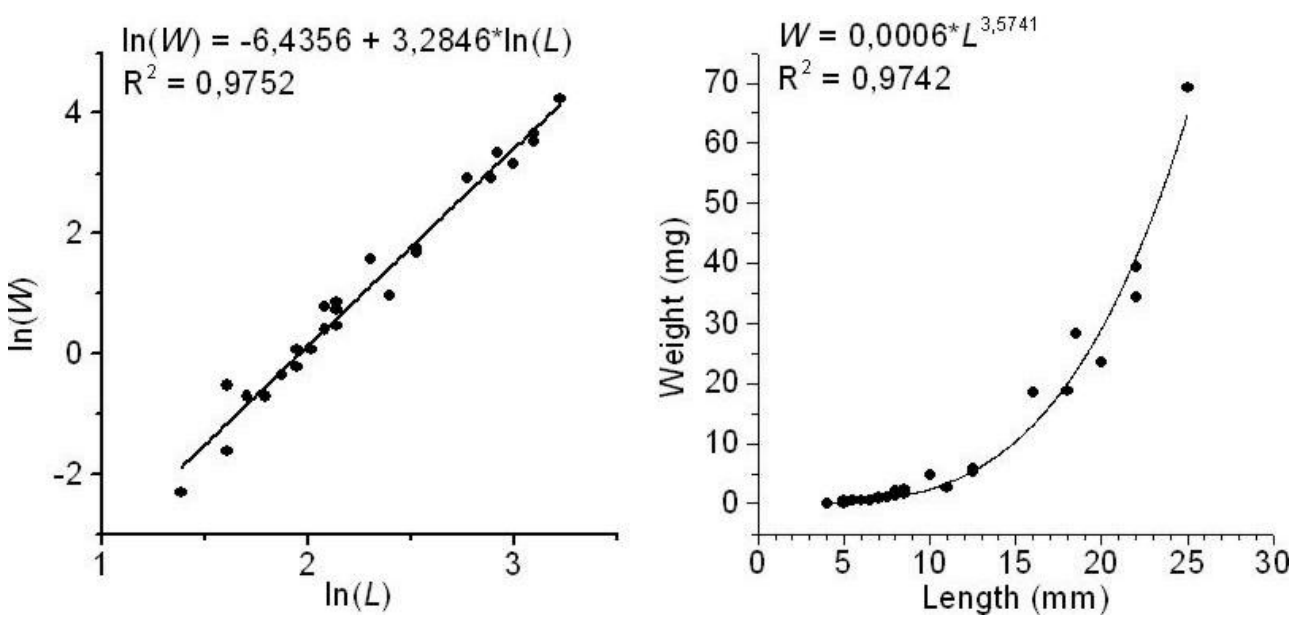

Fig. 4. Length-weight linear regression (left) and power regression (right) for type III larvae.

Confidence curves provided the basis for plotting graphs for each larvae type (Fig. 5). These graphs show the body weight range for larvae of a given length with a probability of $95 \%$. Table 2 lists examples of larval dry mass ranges for the $95 \%$ confidence level.

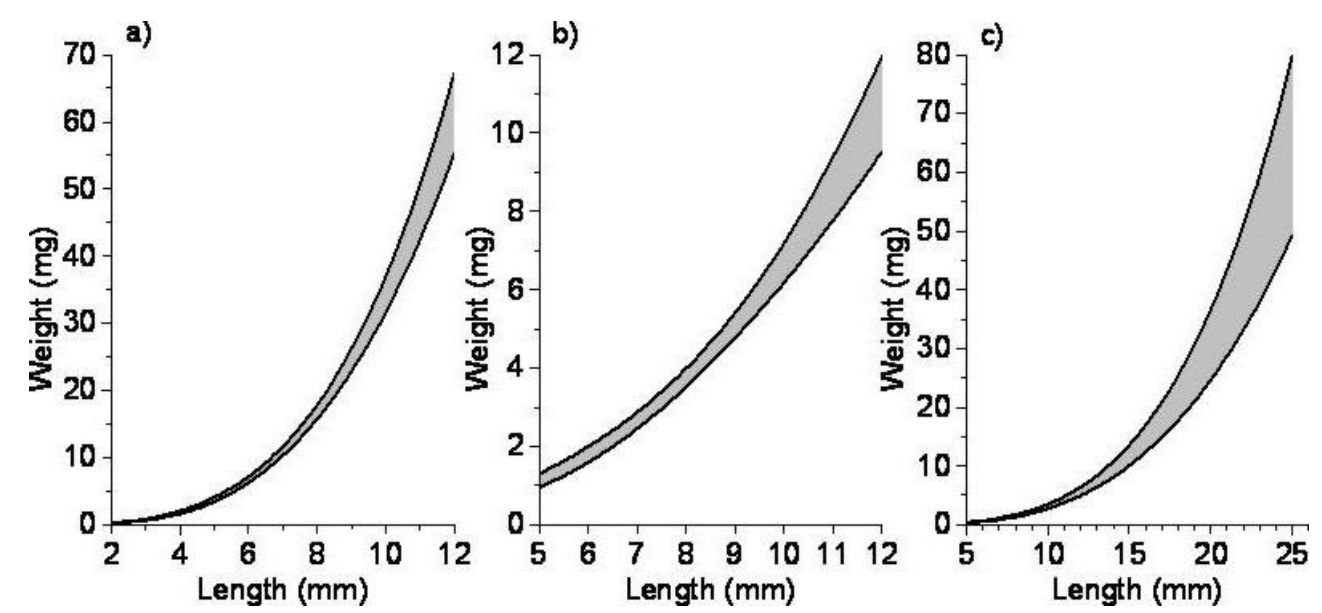

Fig. 5. Dry weight ranges in the confidence interval $95 \%$ for the larvae of types I (a), II (b) and III (c). 
Table 2. Dry weight ranges [mg] for three morphological types of larvae for selected body lengths within the $95 \%$ confidence interval.

\begin{tabular}{|c|c|c|c|c|c|c|c|}
\hline Type & $\mathbf{2} \mathbf{~ m m}$ & $\mathbf{5} \mathbf{~ m m}$ & $\mathbf{8} \mathbf{~ m m}$ & $\mathbf{1 2} \mathbf{~ m m}$ & $\mathbf{1 6} \mathbf{~ m m}$ & $\mathbf{2 0} \mathbf{~ m m}$ & $\mathbf{2 4} \mathbf{~ m m}$ \\
\hline I & $0.2-0.3$ & $3.5-4.1$ & $15.8-17.9$ & $55.4-67.3$ & - & - & - \\
\hline II & - & $1.0-1.3$ & $3.5-4.0$ & $9.5-12.0$ & - & - & - \\
\hline III & - & $0.3-0.4$ & $1.3-1.7$ & $5.0-6.4$ & $12.3-17.0$ & $24.7-36.7$ & $43.4-69.1$ \\
\hline
\end{tabular}

\section{DISCUSSION}

When the slope of the linear function $(b)$ is 3 , there is a linear relationship between larva length and its diameter (assuming that the larva has ideally cylindrical shape). In other words, a larva grows isometrically (when we are dealing with the same larva). When $b>3$, the larval diameter increases faster than the length (the larvae should become "stockier"). On the other hand, when $b<3$, the diameter of the larva increases more slowly than its length (the larva should become more and more "slender"). Assuming that the larva has cylindrical shape (an ideal but non-existent model), parameter $a$ depends on the ratio of the larva's length to its diameter and on its density $\rho$.

The different body proportions of individual species analysed are an important factor modifying the value of $b$. It is also important that insect larvae moult and that their linear dimensions do not increase isometrically with body mass. The body mass usually decreases slightly after moulting owing to the loss of the exuvium (NIJHOUT 1998). For a majority of insects, the value of $b$ is close to 3. For adult forms of Carabidae $b=3.32$ (JAROŠIK 1989), Tenebrionidae $b=2.68$, Curculionidae $b=3.05$ (Rogers et al. 1977), Scarabaeoidea $b=3.32$, etc. However, for some larvae of aquatic insects, the value of $b$ is less than 1.5 or greater than 4.5 (MISERENDINO 2001). The values of parameter $b$ obtained in this work (assuming a linear model for analytical purposes) are significantly different from 3 , for type I ( $p$-value $=0.02, t=2.413)$, for type II $(p$-value $=0.004, t=3.054)$ and for type III ( $p$-value $=0.02, t=2.608)$. The low value of parameter $b$ obtained for type II larvae $(b=2.58)$ most probably results from the relatively low dry weight gain (and increase in diameter) compared to body length.

C-shaped larvae (type I) that live in dung are represented by more than 100 species in Central Europe. They have a stocky, cylindrical body that widens slightly towards the end (STEBNICKA 1976). Larvae of the Onthophagus LATREILLE, 1802 genus have humps on their rear side. Larvae from the genus Onthophagus are not taken into consideration in this analysis, because they are very rare in the study area. The hump on the body of the this genus affects both the length and weight of the larvae; therefore, we can assume that regression equations (Fig. 2) are also applicable to them. 
The regression equations obtained for type II larvae should be used only for the Sphaeridinae subfamily, which includes all the terrestrial representatives of the Hydrophilidae family. It is highly probable that the dry matter of terrestrial organisms increases with body length much faster than in the case of aquatic organisms (SABO et al. 2010). Sphaeridinae larvae have an oblong body, are oval in cross-section, and have either reduced limbs or none at all. 35 species have been found in Central Europe (LÖBL \& SMETANA 2004). Beetle larvae belonging to the Histeridae family, which occur in dung, belong primarily to the genera Hister LINNAEUS, 1758 and Margarinotus MARSEUL, 1853, and only occasionally to other genera. They differ slightly from Hydrophilidae larvae in shape, and they also have well-developed limbs and distinctly segmented urogomphi. Their body is oblong, tapering slightly or more strongly towards the end. The head is of a different size, but is usually proportionally larger than in Hydrophilidae. In spite of these differences, the ratio of larval body length to dry mass is very close to that of the subfamily Sphaeridinae. We can classify here 24 species from Central Europe (LöBL \& SMETANA 2004). However, regression equations (Fig. 3) are applicable to almost all larvae belonging to this family (with the exception of Plegaderus ERICHSON, 1834 larvae and other larvae with evidently oblong bodies).

The very large Staphylinidae family is represented in dung by several subfamilies Aleocharinae, Oxytelinae, Staphylininae and Tachyporinae. Larvae of species from other subfamilies can also occur here, but they are regarded as incidental. The majority of larvae belonging to this family and dwelling in dung are oblong, with well-developed limbs and urogomphi. However, the proportions of the individual body parts may be different. Urogomphi can be very long (Ontholestes GANGLBAUER, 1895) or very short (Atheta THOMSON, 1858), with the head outline round (Oxytelus GRAVENHORST, 1802) or square (Philonthus CURTIS, 1829). The number of Central European species that regularly dwell in dung is rather difficult to estimate. The regression equations (Fig. 4) are applicable to all larvae belonging to these subfamilies, found in dung in Central Europe.

\section{ACKNOWLEDGEMENTS}

We would like to thank Anna ZADROŻNA for her valuable laboratory help and Eugeniusz BIESIADKA for his perceptive comments and corrections. We are also grateful to Anna MĄDRA for her remarks on histerid larvae. 


\section{REFERENCES}

JAROŠIK V. 1989. Mass vs. length relationship for carabid beetles (Col., Carabidae). Pedobiologia 33(2): 87-90.

LINDNER W. 1967. Ökologie und Larvalbiologie einheimischer Histeriden. Zeitschrift für Morphologie und Ökologie der Tiere 59(4): 341-380.

Löbl I., Smetana A. 2004. Catalogue of Palearctic Coleoptera. Volume 2. Hydrophiloidea Histeroidea - Staphylinoidea. Apollo Books, Stenstrup.

Lово J. 1993. Estimation of dung beetle biomass (Coleoptera: Scarabaeoidea). European Journal of Entomology 90(2): 235-238.

MARCUZZI G. 1987. Weight/length ratio in coleopterous insects. Elytron 1: 17-23.

MisERENDINO M.L. 2001. Length-mass relationships for macroinvertebrates in freshwater environments of Patagonia (Argentina). Ecologia Austral 11(1): 3-8.

Nijhout F.H., 1998. Insects Hormones. Princeton University Press, Princeton, New Jersey.

Rogers L.E., Buschbom R.L., WATSON C.R. 1977. Length-weight relationships of shrub-steppe invertebrates. Annals of the Entomological Society of America 70(1): 51-53.

Rogers L.E., Hinds W.T., Buschbom R.L. 1976. A general weight vs. length relationship for insects. Annals of the Entomological Society of America 69(2): 387-389.

SABo J.L., Bastow J.L., Power M.E. 2002. Length-mass relationships for adult aquatic and terrestrial invertebrates in California watershed. Journal of the North American Benthological Society 21(2): 336-343.

Saint-Germain M., Buddle C.M., Larrivée M., Mercado A., Motchula T., Reichert E., Sackett T.E., Sylvain Z., WebB A. 2007. Should biomass be considered more frequently as a currency in terrestrial arthropod community analyses? Journal of Applied Ecology 44(2): $330-339$.

SCHOwALTER T.D. 2011. Insect Ecology. An Ecosystem Approach. Academic Press, London.

Staniec B., Pietrykowska-Tudruj E. 2010. The first description of Bisnius nitidulus (GrAVENHORST, 1802) (Coleoptera: Staphylinidae). Genus 21(2): 205-217.

Stebnicka Z. 1976. Keys for the determination of insects of Poland. Part XIX, 28a: Beetles Coleoptera. Scarabaeidae. PWN, Warszawa. (in Polish)

Thompson D.W. 1917. On growth and forms. Cambridge University Press, England.

VERdú J.R., GALANTE E. 1999. Larvae of Ataenius (Coleoptera: Scarabaeidae: Aphodiinae): Generic characteristics and species descriptions. European Journal of Entomology 96(1): 57-68.

Received: 29 December 2015

Accepted: 22 June 2016 